\title{
Design and experimental validation of improved grapevine burying machine
}

\author{
Shuming Yang,, Huiyan She, Shuchuan Yang, Xuejun Zhu, Yun Chen, Jinhai Li, Maoqiang Li \\ (School of Mechanical Engineering, Ningxia University, Yinchuan 750021, China)
}

\begin{abstract}
In order to address the low soil breaking rate, poor soil covering performance, and low working efficiency of the existing 3MT-1.8 and PMT-75 grapevine burying machines, two types of improved burying machines, namely the 3MTLJ-1.8 and 3MTXP-1.8, were developed in consideration of the local Ningxia soil conditions. Field experimental results indicated that the soil breaking rate of the 3MTLJ-1.8 machine was $71.44 \%$, and its soil sampling volume increased by approximately $30 \%$ compared to that of the 3MT-1.8 machine. It was verified that the self-developed 3MTLJ-1.8 machine can be used in the southern regions of Ningxia. Furthermore, the soil sampling volume of the 3MTXP-1.8 burying machine was $0.24 \mathrm{~m}^{3} / \mathrm{m}$, and its soil breaking rate increased by more than $41.42 \%$ compared to the standard required volume. The $3 \mathrm{MTXP}-1.8$ machine can be used in the northern areas of Ningxia, where the soil hardness is higher. The results can provide a reference for the development and popularization of grapevine burying machines in Ningxia.
\end{abstract}

Keywords: grapevine burying machine, improvement, soil sampling performance, soil covering performance, soil breaking rate DOI: $10.25165 /$ j.ijabe.20181102.2927

Citation: Yang S M, She H Y, Yang S C, Zhu X J, Chen Y, Li J H, et al. Design and experimental validation of improved grapevine burying machine. Int J Agric \& Biol Eng, 2018; 11(2): 95-100.

\section{Introduction}

Ningxia is located in the northwestern part of China. The grape growing areas cover a total of $29333 \mathrm{hm}^{2}$; of which, wine grape growing areas cover a total of $25000 \mathrm{hm}^{2[1]}$. The grape industry has become an essential pillar for rural economic development in Ningxia. Grapevines are vulnerable to cold damage at low temperatures ${ }^{[2-7]}$. There are some very good and long standing management practices that can help reduce the risk of incurring cold damage during the winter ${ }^{[8]}$. Examples of these include: using wind machines to mix the air near the field to eliminate temperature inversion ${ }^{[9]}$; planting cold hardy cultivars in the respective cold hardiness adapted zones; delayed pruning; planting windbreaks around a vineyard to allow more snow to drift into the vineyard to insulate the soil and lower trunk; painting silver or white paint on the south and southwest sides of trunks ${ }^{[10,11]}$; burying vines with soil; spraying amigo oil onto unpruned vines ${ }^{[13]}$; and even wrapping the vine with insulation, with a thermostatically controlled electric heating unit under each vine's insulation ${ }^{[8]}$.

The most commonly used method for protecting grapevines in Ningxia is burying vines, because the soil is environmentally friendly and completely harmless to grapes. Every winter, the grapevines are removed from the trellis and laid on the ground to be covered with soil for insulation ${ }^{[14]}$. However, burying grapevines

Received date: 2016-10-18 Accepted date: 2017-08-20

Biographies: Huiyan She, Master candidate, research interests: modern agricultural equipment, Email: 1014617206@qq.com; Shuchuan Yang, Professor, research interests: modern agricultural equipment, Email: 2407266242@qq.com; Xuejun Zhu, Professor, research interests: modern agricultural equipment, Email: zhuxuejunnxu@sina.com; Yun Chen, PhD, research interests: modern agricultural equipment, Email: 935762276@qq.com; Jinhai Li, Master candidate, research interests: modern agricultural equipment, Email: 772900107@qq.com; Maoqiang Li, PhD, Lecturer, research interests: modern agricultural equipment, Email: 760868792@qq.com.

*Corresponding author: Shuming Yang, PhD, Professor, research interests: intelligent detection and precision agriculture. School of Mechanical Engineering, Ningxia University, Yinchuan 750021, China. Tel: +86-13629571053, Email: shmyang@163.com. is an extremely labor-intensive and time-consuming practice ${ }^{[15-20]}$. Therefore, it is important to achieve the mechanization of the grapevine-burying operation in order to improve the efficiency of grape production in Ningxia ${ }^{[21]}$.

Existing grapevine burying machines in Ningxia exhibit certain disadvantages, such as low soil breaking rate, poor soil covering performance, and low working efficiency ${ }^{[22]}$. In order to address these issues, two improved burying machine models were developed, namely, the 3MTLJ-1.8 and 3MTXP-1.8. Following development, soil sampling and soil covering performance tests were conducted.

\section{Research status of grapevine burying machines in China}

Various burying machines have been used and, to a certain extent, have addressed the problems of high labor intensity, poor covering performance, and low working efficiency. The representative grapevine burying machines available in the domestic market are described in the following subsections.

\subsection{MP-500 grapevine burying machine}

The 1MP-500 burying machine (Figure 1) was developed by the Agriculture Eighth Division of Xinjiang Group in 2007. This machine mainly consists of a soil-extraction and soil-moving component, and it is powered by an $18.4-22 \mathrm{~kW}$ wheeled tractor. The soil sampling volume is adjusted by controlling the working depth of the rotary plow to meet the agronomic requirements of grapevines ${ }^{[23-25]}$. Experimental results using the $1 \mathrm{MP}-500$ burying machine have shown that this model offers the advantages of effective working performance and high working efficiency. However, owing to its large body, it requires a great deal of space in which to turn around when it nears the edge of the field.

\subsection{MT200-2 grapevine burying machine}

The MT200-2 burying machine (Figure 2) was developed by the Tianjin Agricultural Machinery Research Institute in 2004. It is characterized by its high reliability and stability, but exhibits the following two problems. Firstly, it is a dual soil-throwing machine; 
therefore, it requires grapes to be planted with fixed row spacing. If the row spacing changed, the working quality would be affected. Secondly, this machine also requires a large space in which to turn around owing to its $18.4-22.1 \mathrm{~kW}$ wheeled tractor ${ }^{[26,27]}$.

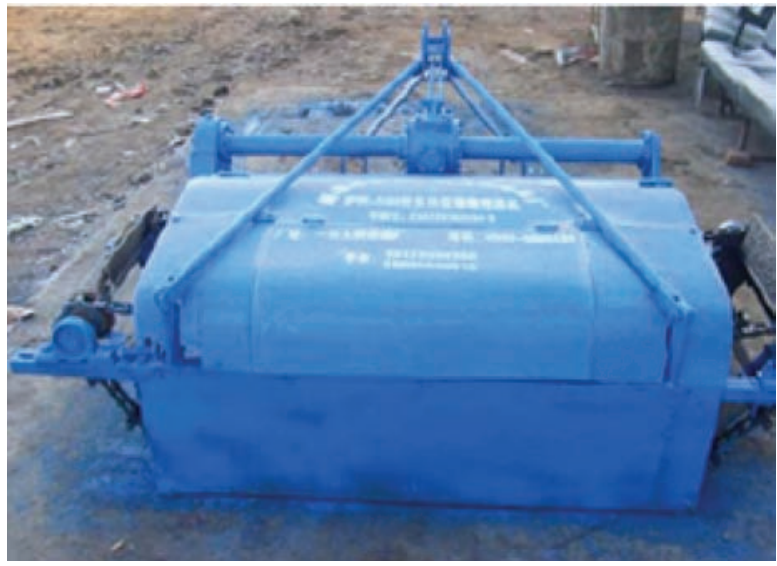

Figure 1 1MP-500 grapevine burying machine

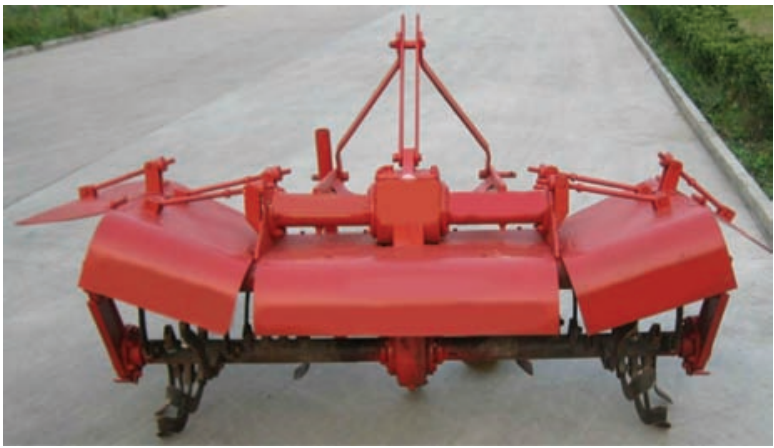

Figure 2 MT200-2 grapevine burying machine

\subsection{PMT-75 grapevine burying machine}

The PMT-75 burying machine (Figure 3) was designed by the Beijing Modern Agricultural Science and Technology Co., Ltd in 2009. It has a side driving design and consists of a gearbox, rotary knife shaft, rear suspensions, shell, longitudinal soil delivery strap, lateral soil delivery strap, and frame, along with other components. It is mainly used for soil covering when the row spacing is greater than $2.6 \mathrm{~m}$. The machine operates as follows: the power transmitted by the wheeled tractor is delivered to the gearbox through a universal joint in order to rotate the knife shaft. The soil is moved from the longitudinal to lateral soil delivery strap. The lateral soil delivery strap then transports the soil and selectively distributes it to the grapevine sides. Although it is more effective in burying grapevines and offers greater applicability, the machine still needs to be improved as a result of its poor stability and reliability ${ }^{[27,28]}$

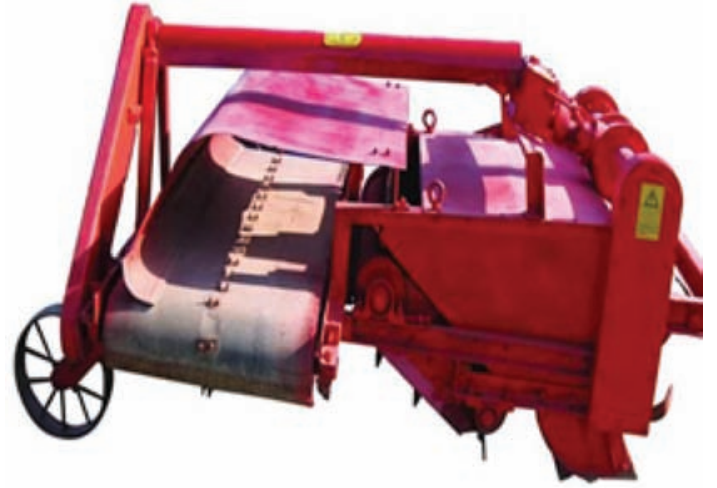

Figure 3 PMT-75 grapevine burying machine

\subsection{MT-1.8 grapevine burying machine}

The 3MT-1.8 burying machine (Figure 4) was developed by the Beijing Fangshan District Agricultural Machinery Research Institute. It is matched with a $22-36.8 \mathrm{~kW}$ tractor and can be used in areas with row spacing of $1.8 \mathrm{~m}, 2.0 \mathrm{~m}$, or $2.5 \mathrm{~m}^{[29]}$. Its working principle is unilaterally burying grapevines, by burying one row of vines from two sides; therefore, the tractor travels twice to bury one row of vines. However, this machine has a low working efficiency and certain application limitations.

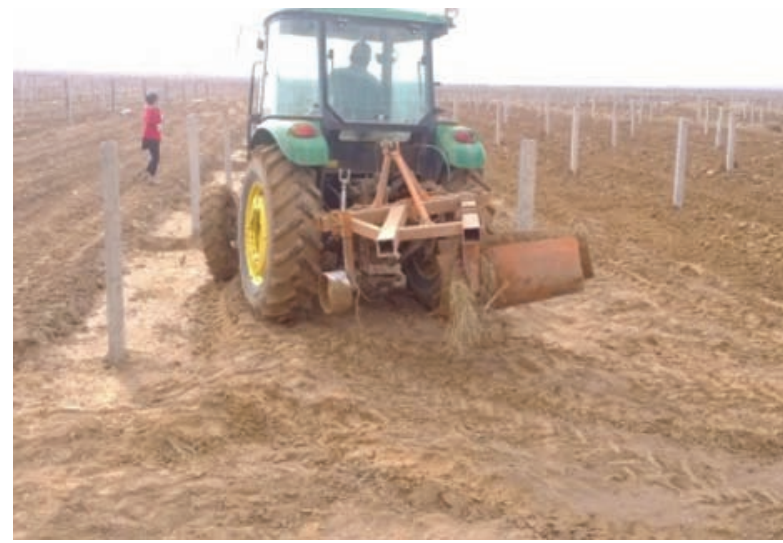

Figure $4 \quad 3 \mathrm{MT}-1.8$ grapevine burying machine

Each machine described above exhibits disadvantages, as there are large variations in factors such as climate, vine growth conditions, vine thickness, and soil hardness, all of which depend on where the machine is used. Furthermore, each machine has varying adaptability for different regions. It has been observed that the grapevine burying machines currently used in Ningxia have low soil breaking rates, poor soil covering performance, and low working efficiency. Therefore, new machines need to be developed based on the existing machines introduced herein.

\section{Improvement of introduced grapevine burying machine}

\subsection{Agronomic requirements of grapevine burying}

The grapevine root system spreads with a large branching angle, numerous vertical roots, and deep soil penetration. Grapevines are generally distributed within $40 \mathrm{~cm}$ of the vine root. Both sampling and burying should be performed at a certain distance from the root in order to avoid damage ${ }^{[30,32,33]}$. According to the local agronomic standard, the thickness and width of the soil in which the grapevine is buried should not be less than $20 \mathrm{~cm}$ and $110 \mathrm{~cm}$, respectively ${ }^{[31]}$. Before the grapevine is buried, it is first pruned and then placed down into the ground ${ }^{[34,35]}$. According to the Ningxia cultivation regulations for wine grapes, the vine burying work should be carried out from late October to early November.

\subsection{Development of 3MTLJ-1.8 grapevine burying machine}

3.2.1 Introduction of 3MT-1.8 grapevine burying machine

Experiments were conducted with the 3MT-1.8 burying machine introduced in this paper and the results indicate a low breaking rate of only $66.07 \%$ and soil sampling volume of $0.20 \mathrm{~m}^{3} / \mathrm{m}$. Therefore, the machine is unable to meet the agronomic requirements.

3.2.2 Improvement of 3MT-1.8 grapevine burying machine

In order to address the low soil breaking rate and poor soil sampling stability of the 3MT-1.8 burying machine, as well as to optimize the machine, the plow was restructured by providing the plow wings with a saw-toothed shape. Furthermore, the number 
of saw teeth on the fore plow was greater than that of the rear plow. The machine comprises a frame, depth wheel device, and plow body. The plow body consists of a plowshare, plow breast, landside plate, plow body frame, and plow leg. The depth wheel device, which consists of a depth wheel and connecting rod, was installed on one side of the center frame. A 3D model of the machine is illustrated in Figure 5.

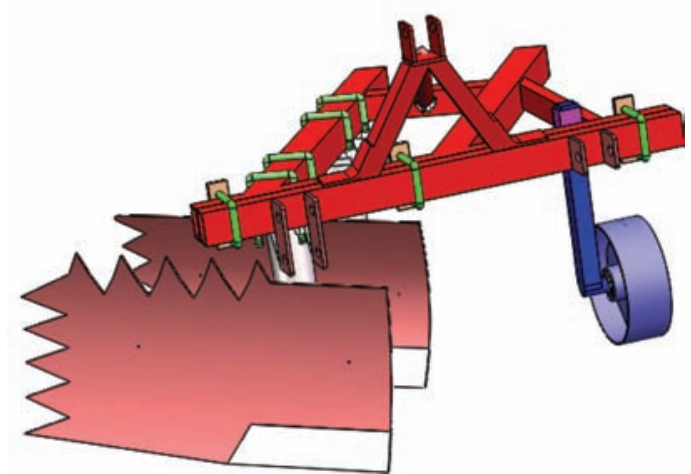

Figure 5 3D model of 3MTLJ-1.8 grapevine burying machine

3.2.3 Working principles of 3MTLJ-1.8 grapevine burying machine

The machine is hung from the rear end of the tractor by using a three-point suspension system. Its operation can be described as follows: the plowshare tip first penetrates the soil, and then, the cutting blade cuts the soil in the horizontal direction. The soil then moves along the plow surface, up to the plow breast, which breaks up and upturns the soil. The plow landside is located below and behind the plow body, clinging to the furrow wall as it buries the grapevines. Meanwhile, the plow landside bears and balances the lateral force from the furrow wall and part of the vertical pressure from the ground. The plow body frame consists of connectors for the plowshare ${ }^{[34]}$, plow breast, landside, plow body frame, and plow leg ${ }^{[36]}$, and it plays an important role in supporting and transferring forces. The plow body is installed on the frame through the plow leg, which transmits power from the frame to the plow body, thus driving it to work.

Compared with the 3MT-1.8 grapevine burying machine, the improved 3MTLJ-1.8 not only increases the soil breaking rate, but also reduces the soil turn resistance, resulting in improved soil breaking performance and soil sampling stability.

Main technical parameters

The main technical parameters of the 3MTLJ-1.8 burying machine are listed in Table 1.

Table 1 Main technical parameters of the 3MTLJ-1.8 grapevine burying machine

\begin{tabular}{ll}
\multicolumn{1}{c}{ Items } & \multicolumn{1}{c}{ Parameter } \\
\hline Auxiliary power $/ \mathrm{kW}$ & 69.9 \\
Equipment weight $/ \mathrm{kg}$ & $280-300$ \\
Dimensions $($ length $\times$ width $\times$ height $) / \mathrm{mm}$ & $1395 \times 1136 \times 1099$ \\
Connection type & Rear three-point suspension \\
Matching tractor $\mathrm{model}$ & DF954 wheeled tractor \\
Operating speed $/ \mathrm{km} \cdot \mathrm{h}^{-1}$ & 5.11 \\
\hline
\end{tabular}

\subsection{Development of 3MTXP-1.8 grapevine burying machine}

3.3.1 Introduction of PMT-75 grapevine burying machine

Experimental results using the PMT-75 burying machine (Figure 6) indicate that the soil covering width was $87.4 \mathrm{~cm}$, a value that does not meet the standard requirement, and its working efficiency was only $64.83 \mathrm{~m} / \mathrm{min}$. Therefore, this machine exhibits poor soil covering performance and low working efficiency.

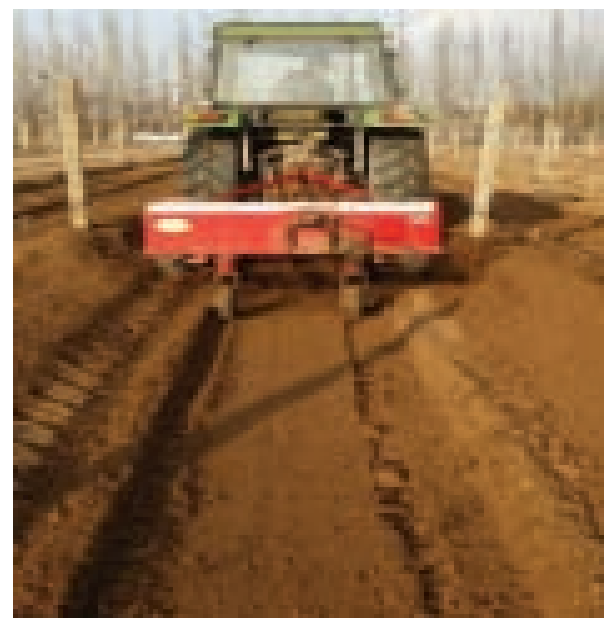

Figure 6 PMT-75 grapevine burying machine

\subsubsection{Improvement of PMT-75 grapevine burying machine}

In order to address the poor soil covering performance and low working efficiency of the PMT-75 burying machine, as well as improve working performance, the soil sampling and soil throwing devices were modified. Combining the characteristics of the plow-type burying machine, with high efficiency and a low breaking rate, and the rotary-type burying machine, with a high breaking rate and low efficiency, the developed machine uses rotational operations to bury grapevines. A small plow was attached at the front of the frame to aid in ditching and scarifying the soil in advance. The developed burying machine was given the model name 3MTXP-1.8, and it mainly comprises a frame, soil throwing disc, shell, gearbox, chain transmission system, and small plow. A 3D model of the machine is shown in Figure 7.

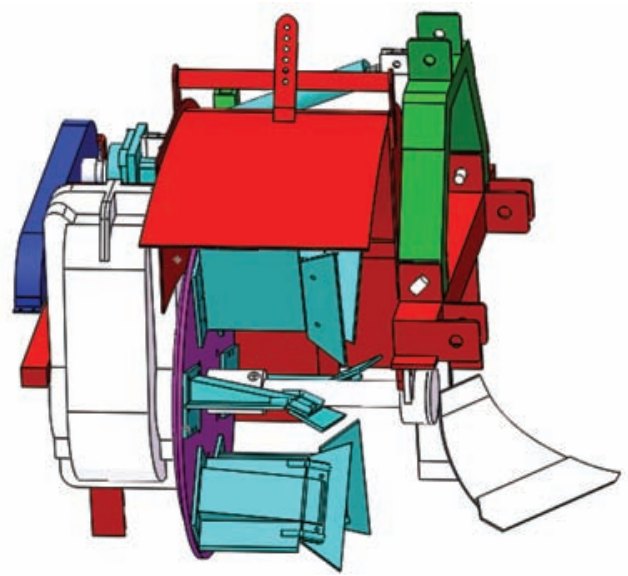

Figure 7 3D model of 3MTXP-1.8 grapevine burying machine

3.3.3 Working principles of 3MTXP-1.8 grapevine burying machine

This machine adopts three-point rear suspension. Power is supplied by the wheeled tractor and delivered to the chain transmission system through the drive shaft, from which power is transmitted to the gearbox through the transmission structure, and finally the soil-throwing disc, equipped with six knives, is rotated. The knife cuts and samples soil when the soil throwing disc rotates. Soil is dispersed by the centrifugal inertia of the disc. During the working process, a small plow in front of the frame aids in ditching and scarifying. This process therefore scarifies, ditches, cuts, samples, and throws the soil in order to bury the grapevine.

Main technical parameters 
The main technical parameters of the 3MTXP-1.8 burying machine are listed in Table 2.

Table 2 Main technical parameters of 3MTXP-1.8 grapevine burying machine

\begin{tabular}{ll}
\multicolumn{1}{c}{ Items } & \multicolumn{1}{c}{ Parameter } \\
\hline Auxiliary power $/ \mathrm{kW}$ & 51.5 \\
Dimensions $($ length $\times$ width $\times$ height $) / \mathrm{mm}$ & $1653 \times 960 \times 1142$ \\
Connection type & Rear three-point suspension \\
Matching tractor model & RK704 wheeled tractor \\
Operating speed $/ \mathrm{km} \cdot \mathrm{h}^{-1}$ & 2.94 \\
\hline
\end{tabular}

\section{Field test}

\subsection{Testing purpose}

In order to investigate field adaptability, working reliability, and the rationality of the machine's mechanism configuration, soil sampling and soil covering performance tests were conducted. The test conditions, which are in accordance with the field test standards of grapevine burying machines in the Ningxia Hui Autonomous Region ("DB64/T 915-2013 grapevine burying

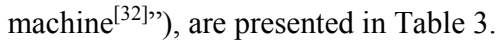

Table 3 Test conditions

\begin{tabular}{ccccc}
\hline Models & Time & Places & $\begin{array}{c}\text { Soil } \\
\text { hardness/Pa }\end{array}$ & $\begin{array}{c}\text { Tractors working } \\
\text { speed } / \mathrm{km}^{-1}\end{array}$ \\
\hline 3MT-1.8 & 2014.11 .1 & Nuanquan Farm & 6.8 & 7.45 \\
PMT-75 & 2014.11 .11 & Nuanquan Farm & 6.8 & 3.89 \\
3MTLJ-1.8 & 2015.8 .14 & Yuquan Farm & 9.29 & 5.11 \\
3MTXP-1.8 & 2015.11 .19 & Hong Sibao & 5.88 & 2.94 \\
\hline
\end{tabular}

\subsection{Soil sampling performance test}

The indices of soil sampling performance include the soil sampling volume, breaking rate, and sampling stability variation coefficient.

\subsubsection{Test method}

The measurement process employed to determine the soil breaking rate can be described as follows. Firstly, five measurement areas with equal spacing were selected along the forward direction. Secondly, in each area, a $30 \mathrm{~cm} \times 30 \mathrm{~cm}$ pitch was randomly selected for measurement along the vertical direction of the trench wall formed by the burying soil. In each measurement, soil clods with lengths greater than $3 \mathrm{~cm}$ were screened out, packed into containers, and weighed; then, the remaining buried soil was packed into the same containers and weighed. The ratio of the two measured weights is the breaking rate. Each experiment was performed five times. The soil breaking rate and average value were calculated according to Equations (1) and (2).

$$
\begin{gathered}
C_{m}=1-G_{m} / G \\
C=C_{m} / n
\end{gathered}
$$

where, $C$ is the soil breaking rate, $\%$; $G$ is the total mass of the throwing clods in the test region, $\mathrm{kg} ; G_{m}$ is the mass of throwing clods greater than $3 \mathrm{~cm}$ in length in the measurement area, $\mathrm{kg}$; $n$ is the number of test trials.

\subsubsection{Test results}

Soil sampling performance tests were carried out according to the method described previously (refer to Figure 8). The test results are summarized in Table 4.

As seen in Table 4, the soil sampling volume of the 3MTLJ-1.8 grapevine burying machine was $0.26 \mathrm{~m}^{3} / \mathrm{m}$; representing a $30 \%$ increase compared to the $3 \mathrm{MT}-1.8$ machine and surpassing the standard requirement of $0.22 \mathrm{~m}^{3} / \mathrm{m}$. The soil breaking rate was $71.44 \%$, which is slightly higher than the standard requirement of $70 \%$, and this was mainly due to the special saw-tooth shape structure of the machine. The saw teeth act as cutters for slicing the soil blocks into pieces. Overall, this machine offers the advantages of a high soil breaking rate and large soil sampling volume, among others. The soil breaking rate of the 3MTXP-1.8 was $99 \%$, which increased by $41.42 \%$ over the standard requirement of $70 \%{ }^{[32]}$. This is because it belongs to a rotary-type burying machine, and therefore more soil blocks are cut before being thrown to the grapevine. The soil sampling volume was $0.24 \mathrm{~m}^{3} / \mathrm{m}$, which is greater than the standard requirement of $0.22 \mathrm{~m}^{3} / \mathrm{m}$. As indicated previously, the 3MTXP-1.8 machine has a high soil breaking rate and exhibits suitable soil sampling performance. The results also indicate that the soil sampling stability variation coefficient of the two improved burying machines was slightly greater than the standard requirement of $10 \%{ }^{[25]}$. However, for the $3 \mathrm{MT}-1.8$ machine, it was only $2.45 \%$, because the soil hardness of the experimental locations differed (refer to Table 3). When the machine was operated in fields with higher soil hardness, the soil sampling height remained broadly consistent under the influence of the depth wheel. However, when the machine was operated in fields with lower soil hardness, the depth wheel easily moved up and down to maintain balance, which means that relative stability could not be maintained.

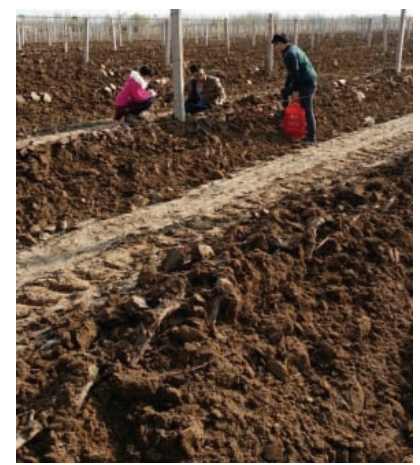

a. 3MT-1.8 machine test

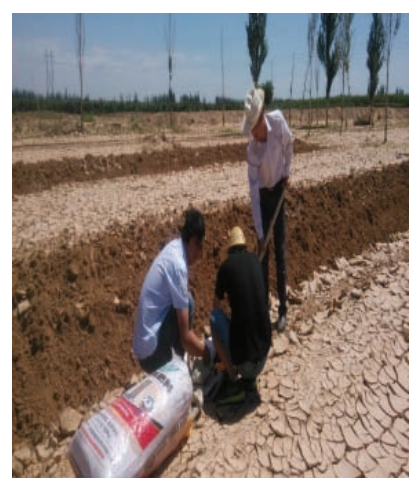

c. 3 MTLJ-1.8 machine test

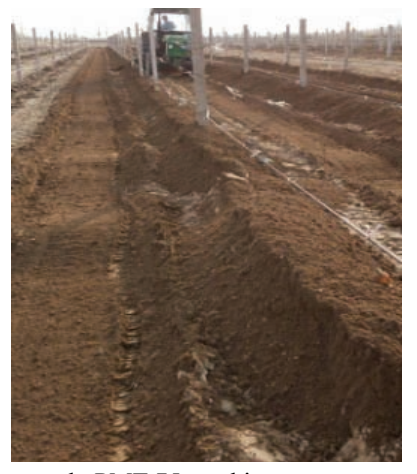

b. PMT-75 machine test

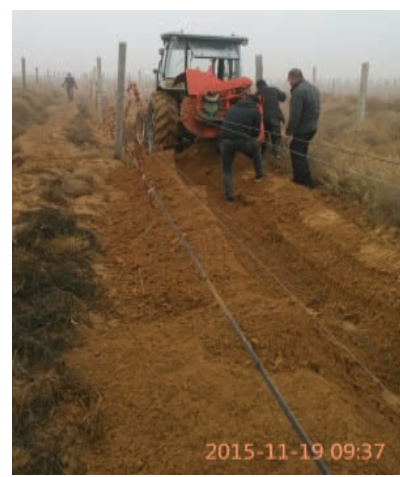

d. 3MTXP-1.8 machine test
Figure 8 Soil sampling performance tests

\begin{tabular}{|c|c|c|c|c|c|}
\hline \multirow{2}{*}{ Items } & \multicolumn{4}{|c|}{ Measured values } & \multirow{2}{*}{$\begin{array}{c}\text { Standard } \\
\text { value }\end{array}$} \\
\hline & 3MT-1.8 & 3MTLJ-1.8 & PMT-75 & 3МТXР-1.8 & \\
\hline $\begin{array}{l}\text { Soil sampling } \\
\text { volume } / \mathrm{m}^{3} \cdot \mathrm{m}^{-1}\end{array}$ & 0.20 & 0.26 & - & 0.24 & 0.22 \\
\hline $\begin{array}{l}\text { Soil sampling stability } \\
\text { variation coefficient } / \%\end{array}$ & 2.45 & 11.54 & - & 13.17 & 10 \\
\hline Soil breaking rate $/ \%$ & 66.07 & 71.44 & 90.95 & 99 & 70 \\
\hline
\end{tabular}

Table 4 Results of soil sampling performance test 
Whether the vines could be protected from winter cold injury mainly depends on the amount of soil that the grapevine was buried in and the soil covering thickness.

\subsection{Soil covering performance test}

The soil covering performance indices include soil throwing distance, covering thickness, and covering width.

\subsubsection{Test method}

The soil throwing distance was obtained by measuring the vertical distance from the center of the slice formed by the plow to the adjacent trench wall. The soil covering thickness and width were obtained by measuring the section thickness and width, respectively.

\subsubsection{Test results}

Figure 9 shows the soil covering performance tests, which were carried out as previously described, and the results are presented in Table 5 .

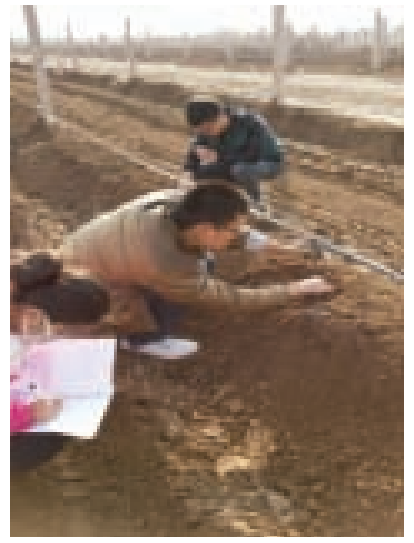

a. $3 \mathrm{MT}-1.8$ machine test

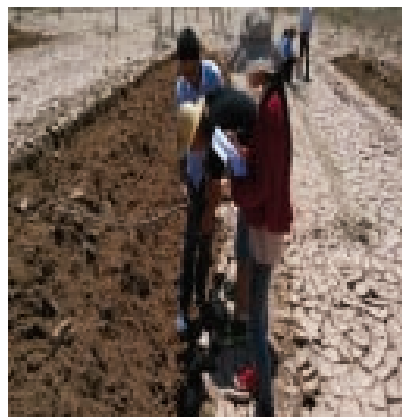

c. $3 \mathrm{MTLJ}-1.8$ machine test

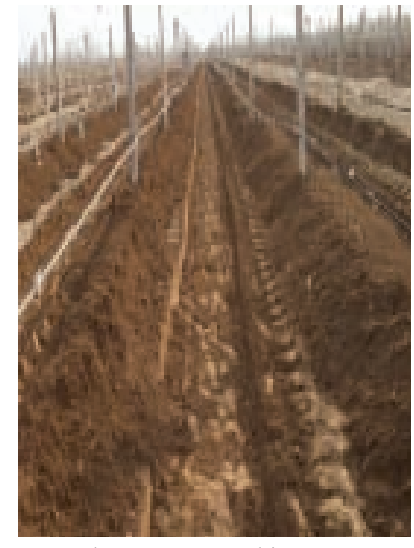

b. PMT-75 machine test

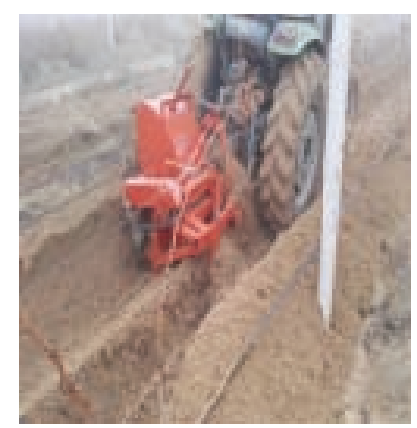

d. 3MTXP-1.8 machine test
Figure 9 Soil covering performance tests

Table 5 Results of soil covering performance test

\begin{tabular}{|c|c|c|c|c|c|}
\hline \multirow{2}{*}{ Items } & \multicolumn{4}{|c|}{ Measured values } & \multirow{2}{*}{$\begin{array}{l}\text { Standard } \\
\text { value }\end{array}$} \\
\hline & $3 \mathrm{MT}-1.8$ & 3MTLJ-1.8 & PMT-75 & 3МTXP-1.8 & \\
\hline $\begin{array}{l}\text { Soil throwing } \\
\text { distance/cm }\end{array}$ & 111.95 & 169 & 182.4 & 86 & 80 \\
\hline $\begin{array}{l}\text { Soil covering } \\
\text { thickness } / \mathrm{cm}\end{array}$ & 29 & 34.4 & 26.8 & 29.5 & 20 \\
\hline $\begin{array}{l}\text { Soil covering } \\
\text { width } / \mathrm{cm}\end{array}$ & 127.8 & 184.5 & 87.4 & 138 & 110 \\
\hline
\end{tabular}

The following observation can be made from Table 5: (a) the soil throwing distance of the 3MTLJ-1.8 machine was $169 \mathrm{~cm}$, which is longer than the standard requirement of $80 \mathrm{~cm}$; (b) the soil throwing width was $184.5 \mathrm{~cm}$, which is wider than the standard requirement of $110 \mathrm{~cm}$; and (c) the soil throwing thickness was $34.4 \mathrm{~cm}$, which is larger than the standard requirement of $20 \mathrm{~cm}$. Because all these parameters met the standard requirements, the 3MTLJ-1.8 machine demonstrated effective performance with respect to soil covering. In addition, the soil throwing distance of the 3MTXP-1.8 burying machine was $86 \mathrm{~cm}$, the width was $138 \mathrm{~cm}$, and the thickness was $29.5 \mathrm{~cm}$. Therefore, all the parameters of the 3MTXP-1.8 machine also met the requirements. This indicates that the soil covering performance of the machine meets the agronomic requirements when burying grapevines during winter.

\section{Conclusions}

Two grapevine burying machines, namely the 3MTLJ-1.8 and 3MTXP-1.8, were developed, and experiments were conducted for comparison with the introduced machines. With its special saw-tooth shape structure, the 3MTLJ-1.8 machine offered an additional cutting function without requiring extra parts. The 3MTXP-1.8 machine took full advantage of the plow- and rotary-type burying machines.

The results indicate that the development of the 3MTLJ-1.8 grapevine burying machine could improve the soil breaking rate. It exhibited a high working efficiency, good soil sampling performance, and high soil breaking rate. The soil hardness varies from the south to the north in Ningxia, but on the whole, it is lower in the southern regions than in the north. Therefore, the machine is suitable for use in the southern regions of Ningxia. The development of the 3MTXP-1.8 machine could also improve working efficiency and soil sampling stability. Although this machine met the agronomic requirements, knife shaft failure is likely to occur when breaking larger stone blocks. It is therefore suitable for grape planting areas characterized by high-hardness loam soil, without stone blocks, in the northern regions of Ningxia. The development of the proposed grapevine burying machines has a significant effect on improved grape production efficiency in Ningxia.

\section{Acknowledgments}

The authors acknowledge that this research was financially supported by the Ningxia Hui Autonomous Region Science and Technology Support Plan Project, 2015BY11102.

\section{[References]}

[1] Zhao R L, He W L. Situation and development measures of grape production mechanization in Ningxia. Chinese Agricultural Mechanization, 2012; 6: 15-18. (in Chinese)

[2] Wisniewski M, Gusta L V. The biology of cold hardiness: Adaptive strategies. Environ Exp Bot, 2014; 106: 1-3.

[3] Spayd S E. Wine-grape cold injury assessment in post-bud break period. HortScience, 2007; 42(4):795-796.

[4] Bucur G M, Dejeu L. Research on frost injury of new Romanian grapevine cultivars in the winter 2014-2015. Agriculture and Agricultural Science Procedia, 2016; 10: 233-237.

[5] Dami I E, Ennahli S, Zhang Y. Assessment of winter injury in grape cultivars and pruning strategies following a freezing stress event. American journal of enology and viticulture, 2012; 63(1): 106-111.

[6] Molitor D, Caffarra A, Sinigoj P, Pertot I, Hoffmann L, Junk J. Late fros damage risk for viticulture under future climate conditions: a case study for the Luxembourgish winegrowing region. Australian Journal of Grape and Wine Research, 2014; 20(1): 160-168.

[7] Frioni T, Green A, Emling J E, Zhuang S, Palliotti A, Sivilotti P, Sabbatini P. Impact of spring freeze on yield, vine performance and fruit quality of Vitis interspecific hybrid Marquette. Scientia Horticulturae, 2017; 219: 302-309.

[8] Zabadal T J, Dami I E, Goffinet M C, Martinson T E. Winter injury to grapevines and methods of protection. Chien M L: Michigan State University Extension; 2007.

[9] Hu Y G, Wu W Y, De Melo-Abreu J P, Shapland T M, Zhang H, Snyder R 
L. Comparative experiments and effectiveness evaluation on vertical blowing fans (VBF) for frost protection. Int J Agric \& Biol Eng, 2015; 8(5): 36-42.

[10] Londo J P, Kovaleski A P. Characterization of wild North American grapevine cold hardiness using differential thermal analysis. American Journal of Enology and Viticulture, 2017; 68 (2): 203-212.

[11] Ker K. Ontario's experience with wind machines for winter injury protection of grapevines and tender fruit. In: Proc. of Inst. For Continental Climate Viticulture and Enology-Understanding and preventing freeze damage in vineyards, 2007; pp.75-78.

[12] Zhang Y, Dami I. Improving freezing tolerance of 'chambourcin' grapevines with exogenous abscisic acid. Hortscience, 2012; 47(12): $1750-1757$.

[13] Loseke B A, Read P E, Blankenship E E. Preventing spring freeze injury on grapevines using multiple applications of Amigo Oil and naphthaleneacetic acid. Scientia Horticulturae, 2015; 193: 294-300.

[14] Li T, Kang J, Zhao W Y, Sun W, Zhang F W, Zhang J L, et al. Design of a new grape vine overwintering burying machine. Acta Agriculturae Boreali-Occidentalis Sinica, 2013; 22(8): 151-156.

[15] Li T, Kang J, Wu J M, Sun W, Lv X M. The present situation of grape vine burying machine and the development of related mechanization technology in China. Journal of Agricultural Mechanization Research, 2013; 10(10): 218-221. (in Chinese)

[16] Liu Z J, Yang X J, Liu L J, Jia Z H, Zhang T. Grape vine winter buried soil machine design. Journal of Agricultural Mechanization Research, 2012; 2(2): 113-115. (in Chinese)

[17] Evans R G. The art of protecting grapevines from low temperature injury. Proc. ASEV 50 ${ }^{\text {th }}$ Anniversary Annual Mtg., Seattle WA, 2000; pp.60-72.

[18] Spring P E B. Cold injury to winegrapes and protection strategies and methods. Hortscience, 2008; 43(6): 1652-1662.

[19] Meng H W, Li J J, Kan Z. Development of PM-1200 suspended grape vine burying machine. Journal of Agricultural Mechanization Research, 2012; 6: 53-55. (in Chinese)

[20] Lu H Y. The present situation and development of the technology of grape vines. Agricultural Machinery, 2013; (12): 174-175. (in Chinese)

[21] Ning S C. Selection and operation technology of grape vine burying machine. China Agricultural Mechanization Herald, 2012; 5: 1-2. (in Chinese)

[22] You J, Hu J, Guo H, Yang W Z. Development of a new type grape vine burying machine. Agricultural Engineering, 2014; 5(3): 100-103. (in
Chinese)

[23] Zhao R L, Wang L, Tan Z B. Design and development of the grape vine burying machine. Journal of Agricultural Mechanization Research, 2012; 12(12): 115-119. (in Chinese)

[24] Zhang H Q. Development of 3MT-5.0 grape vine burying machine. Agricultural Science \& Technology and Equipment, 2013; 11(11): 44-46. (in Chinese)

[25] Zhang J, Li X B. 1MP-500 multi-function grape vine machine. Xinjiang Agricultural Mechanization, 2008; 1: 37. (in Chinese)

[26] Liu Z G. Technology of grape vine burying machine. Agricultural Technology and Equipment, 2007; 8: 23. (in Chinese)

[27] Pang J J, Ning S C, Li Y X. MT200-2 grape vine burying machine and operation technical key points. Xinjiang Agricultural Mechanization, 2006; 2: 70-71. (in Chinese)

[28] You J, Guo H, Hu J, Yang W Z. Review of grape vine burying machine. Agricultural Engineering, 2013; 3(2): 8-10. (in Chinese)

[29] Wang Z Q, Hao Z Q, Liu F Z. Grape overwintering machine development and trend of management machinery. Agricultural Technology and Equipment, 2014; 6B: 4-6. (in Chinese)

[30] Pang J J, Gou H M, Ning S C. Grape mechanization buried rattan technology and its development in China. Sino-overseas Grapevine \& Wine, 2008; 3: 32-33. (in Chinese)

[31] Liu Z J. Design and research on grape vine machine. Beijing: Chinese Academy of Agricultural Mechanization Sciences, 2011; 7: 1-9. (in Chinese)

[32] DB64/T 915-2013, Local standards and technical indicators of grape vine burying machine. Quality and Technical Supervision in Ningxia Hui Autonomous Region, 2013. (in Chinese)

[33] Li T, Kang J, Sun W, Zhao W Y, Wang D, Zhang J L, et al. Design and test on a new grape vine over-winter burying machine. Agricultural Research in the Arid Areas, 2013; 31(4): 249-256. (in Chinese)

[34] Shang S Q, Wang D W, Lu G Y. Current situation and development trend of grape mechanization production. China Agricultural Mechanization Herald, 2014; 5(7): 7-9. (in Chinese)

[35] Sun P F. Design and performance research of the shovel and throw type grape vine burying machine. Agricultural University of Hebei, 2014. (in Chinese)

[36] Ding W M. Agricultural Machines. Beijing: China Agriculture Press, 2011. (in Chinese) 